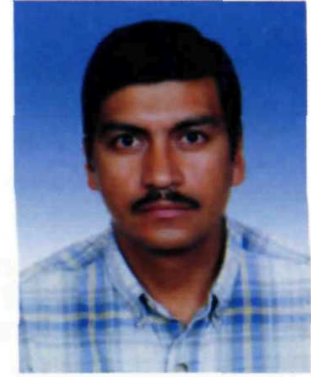

Ing. Agr. Daniel Ortiz Gómez Representante de FARMAGRO

uchas veces nos hemos dado cuenta que el producto químico adquirido (fungicida, insecticida, herbicida, etc.) no funciona como esperábamos, entonces 10 más fácil es pensar que ya no lo están fabricando como antes, han bajado el porcentaje del ingrediente activo o simplemente que lo están falsificado, pero la realidad es que intervienen varios factores para que este agroquímico no trabaje como es debido.

Para que un plaguicida (nombre que se dá a cualquier producto químico que sirve para contrarrestar un problema en los cultivos) ejerza su acción toxica sobre el agente que queremos controlar, se debe tomar en cuenta los siguientes puntos:

Retención.- el producto debe permanecer sobre la superficie del área tratada el suficiente tiempo para producir los efectos para el cual fue elegido. Esto puede ser traducido como efecto total o mayor protección, como en el caso de los herbicidas, y que en la mayoría de casos se mejora con el uso de COSMO IN D como surfactante.

Penetración.- con este término se puede referir a la retención del pro-

\section{El agua en}

\section{la agricultura}

ducto en el medio, que puede ser el suelo, el follaje de la planta; y, el segundo, al ingreso mismo dentro de los individuos a controlar, lo que requiere varias vías, tales como: estructura reproductivas de los hongos, espiráculos en los insectos o la lámina foliar en el caso de los herbicidas, etc. Un mejor resultado se obtiene con el uso de COSMO IN D.

Traslocación.- en este caso se menciona a los productos cuya actividad se manifiesta mediante el desplazamiento interno hacia los puntos en los cuales se ejerce su acción (sistémicos o trasloca-bles), es necesario que el producto penetre y luego se desplace para lograr la eficiencia del producto.

Efecto Tóxico.- debemos conocer si el producto interfiere en algún proceso biológico o bioquímico para saber si va o no a ejercer su control.

El pH del agua.- toda agua tiene su pH propio, es recomendable medir con la ayuda de las cintas indicadoras o con un reactivo el valor del $\mathrm{pH}$, además hay que tener en cuenta que los agroquímicos están fabricados para actuar mejor en medios ácidos.

\section{Uso de los Coadyuvantes}

A pesar del avance tecnológico que vamos teniendo últimamente, el término coadyuvante se nos hace algo desconocido, lamentablemente todos los organismos (públicos y privados), que nos dedicamos al campo agrícola tenemos parte de culpa por la carencia de información generada. Nos limitamos a darles nombres o sinónimos como "pegantes o fijadores" y no le brindamos la importancia del caso.

EI ICA de Colombia define al coadyuvante como: 
"Toda sustancia que se adiciona a un plaguicida, defoliante o regulador fisiológico para facilitar su acción o conservar sus características físicas o químicas"

Se mencionaron algunos factores que intervienen en la eficacia de un plaguicida, y de acuerdo a la definición de coadyuvante del ICA, nos vemos en la imperiosa necesidad de utilizar un coadyuvante como parte integradora en la mezcla de plaguicidas utilizados en la agricultura, la adición de este producto (COSMO IN D) nos garantiza que la eficiencia de los agroquímicos Ilegue a lo que nosotros esperamos y el control de los agentes enemigos sea satisfactorio.

\section{Calidad del agua para la fumigación}

Hasta hace pocos años, se pensaba que la única función del agua en el caldo de fumigación es la de disolver los productos químicos para luego ser aplicados en el cultivo, esta teoría comienza a perder peso cuando se descubre que la gran mayoría de agroquímicos trabajan mejor en medios ácidos, es decir el agua debe ser tratada para certificar que el control del problema que afecta nuestro cultivo sea el mejor.

Toda agua tiene un $\mathrm{pH}$, la acidez del agua natural es causada por la presencia espontánea o por contaminación con ácidos fuertes como el sulfúrico y el clorhídrico. Lo contrario a la acidez es la alcalinidad, causada por la presencia de bicarbonatos y carbonatos. El valor del $\mathrm{pH}$ permite tener una idea del tipo de sal que da la alcalinidad, valores menores a 4.2 nos indica que el agua no contiene bicarbonatos ni carbonatos, es decir no hay alcalinidad; un $\mathrm{pH}$ comprendido entre 4.2 y 6 indica la presencia de bióxido de carbono, de 7 a 9, de bicarbonatos y los pH superiores a 9 indican presencia de carbonatos y eventualmente hidróxidos.

Dureza.- debido a lo extendido que está la caliza, casi todas las aguas subterráneas contienen concentraciones pequeñas, pero a veces apreciables del catión $\mathrm{Ca}$, lo mismo que de $\mathrm{Mg}$ o $\mathrm{Fe}$; constituyen un inconveniente, ya que cuando a esas aguas se las añade fuentes carbonatadas (Mancozeb) se cortan y forman precipitados insolubles. $E$ agua que así se comporta, se dice que es dura y presenta problemas por el taponamiento de los sistemas de riego, bombas de fumigar y mangueras.

Tabla $\mathbf{N}^{\circ} . \mathbf{1}$

\begin{tabular}{lr}
\hline \multicolumn{2}{|c|}{ Clasificación de la dureza del agua } \\
\hline Denominación & ppm (partes por millón) en carbonato de calcio \\
\hline Blandas & $0-60$ \\
\hline Moredada & $61-120$ \\
\hline Dura & $121 \quad 180$ \\
\hline Muy dura & Más de 180 \\
\hline Fuente: Sociedad Americana de Ingenieros
\end{tabular}

Hoy en día contamos con un producto de excelente calidad que nos ayuda a "curar" el agua antes de incorporar los agroquímicos en el tanque, esto nos permite suponer que la eficacia del producto se va ha acercar a la perfección, en el mercado agrícola se lo comercializa con el nombre de COSMO AGUAS, y se dosifica de acuerdo a los resultados del análisis del agua que se esté utilizando, pero un promedio de $0.3 \mathrm{gr}$. de producto por cada litro de agua es suficiente (60 gr por cada tanque de 200 It de agua.

\section{Tabla $\mathbf{N}^{\circ} \cdot 2$}

\section{Dósis recomendada de COSMO-AGUAS para ADECUAR el pH y la dureza de aguas en la aplicación de agroquímicos}

Dureza inicial (ppm $\left.\mathrm{CaCO}_{3}\right)$

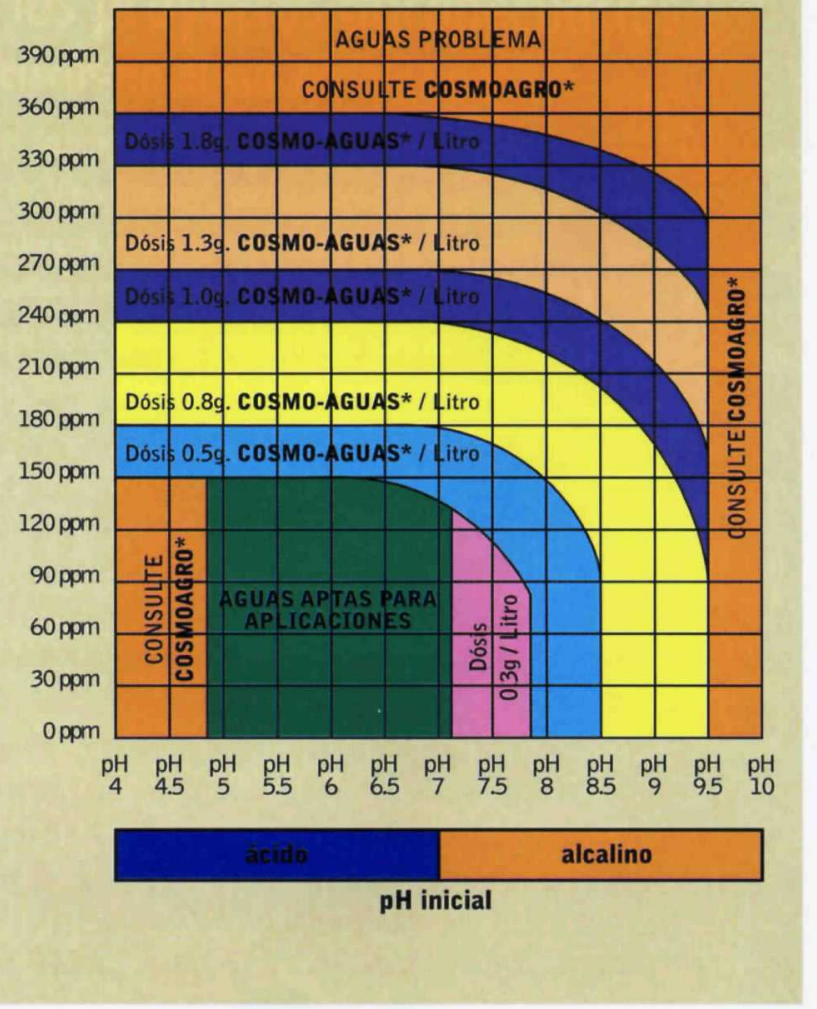

\section{A manera de conclusión}

El agua al ser el principal vehículo utilizado en las aplicaciones de los agroquímicos es necesario que reúna condiciones adecuadas que nos garanticen la eficiencia de los productos, por esta razón, la pareja COSMO AGUAS más COSMO IN D es la recomendación ideal para arreglar el agua, teniendo en cuenta que primeramente incorporamos el COSMO AGUAS, luego el COSMO IN D y luego el resto de productos que se utilizarán en la fumigación. 